\title{
The emergence and utilisation of frailty in the United Kingdom: a contemporary biopolitical practice
}

\author{
Louise Tomkow \\ Humanitarian and Conflict Response Institute, School of Arts Languages and Cultures, University of \\ Manchester, Manchester, UK \\ Email: louise_tomkow@hotmail.com
}

(Accepted 11 September 2018; first published online 8 October 2018)

\begin{abstract}
Frailty has recently emerged as a dominant concept against a backdrop of media and governmental narratives that frame the growing ageing population as an economic threat to the current configuration of health care in the United Kingdom (UK). Despite frailty's popularity amongst geriatricians and policy makers, the concept faces resistance from other health-care professionals and older people themselves. This paper draws on the Foucauldian idea of biopower; by suggesting that the contemporary emergence and utilisation of frailty represents a biopolitical practice a number or critical observations are made. First, despite biomedical experts acknowledging ambiguities in the definition of frailty, the concept is presented as a truth discourse. This is driven by the ability of frailty measurements to predict risk of costly adverse outcomes; the capability of frailty scores to enumerate complex needs; and the scientific legitimacy frailty affords to geriatric medicine. Consequently, frailty has become pervasive, knowable and measurable. Second, the routine delineation between frail and robust objectifies older people, and can be said to benefit those making the diagnosis over those being labelled frail, with the latter becoming disempowered. Last, studies show that frailty is associated with increasing wealth inequalities in the UK; however, experts' suggested management of frailty shifts the focus of responsibility away from ideologically driven structural inequalities towards the frail older person, attempting to encourage individuals to modify lifestyle choices. This neglects the association between lifestyle opportunities and socio-economic deprivation, and the impact of long-term poverty on health. These observations, set against the contemporary political climate of economic austerity, cuts to public services and rationalisation of health resources, bring the urgency of a critical consideration of frailty to the fore.
\end{abstract}

Keywords: frailty; biopolitics; biopower; Foucault; National Health Service; geriatric medicine

\section{Introduction}

Recent interest in frailty has rapidly expanded; it now forms a dominant health paradigm in geriatric medicine and is being positioned as a public health priority

(c) Cambridge University Press 2018 
by policy makers who cite pressures from the ageing population (Cesari et al., 2014). Several studies based on large data-sets have demonstrated the ability of frailty measurement tools to predict adverse outcomes such as unplanned hospitalisation and death. This has made the concept popular with biomedical researchers, health economists and policy makers; the routine identification of frailty from general practice (GP) electronic health records is now part of National Health Service (NHS) England's GP contract. However, there is no universally accepted definition of what frailty actually is and concern about how the concept is being applied is growing. This paper adopts the Foucauldian concept of biopower as a lens, through which the contemporary emergence, and drive towards the routine nosology, of frailty is analysed. Rabinow and Rose's (2003) interpretation of biopower as a theoretical framework allows several critical observations to be made; the paper will begin with a brief overview of this theoretical approach, followed by the main argument, presented in three sections. First, examination of quantitative biomedical studies and NHS England policy documents suggests that, despite conceptual ambiguity, frailty is presented as a truth discourse. As a result, frailty can be used as a tool to render life processes knowable; measuring frailty allows state bodies to enumerate the risk of older people accessing increasingly scarce health resources and thus threatening the existing shape of health-care systems. In addition, frailty offers geriatric medicine legitimacy by positioning geriatricians as frailty experts. Second, by drawing on existing social science literature, it will be suggested that this enumeration, and the resultant categorical delineation between frail and robust individuals, is a dividing practice that objectifies older people. Third, despite the association of frailty with socio-economic deprivation, current frailty interventions shift the weight of responsibility away from modifiable structural causes of health inequalities towards frail individuals, attempting to encourage older people to selfmanage through lifestyle modifications. In the context of the contemporary political climate of austerity, attempting to subjectivate already-marginalised populations is problematic. By considering how the contemporary emergence and application of frailty can be understood as a biopolitical practice, and critically analysing it as such, this paper suggests that frailty as a concept primarily benefits state-led health and economic institutions rather than older individuals.

\section{The contemporary emergence of frailty}

The UK's population is ageing (Office for National Statistics, 2017). Despite the benefits of increasing longevity, older people are often presented as a cost, threat or challenge to the economic sustainability of state health services by governments, medical experts and the media (Laurence, 2002; Press Association, 2005; Silcock and Sinclair, 2012; Campbell, 2015; Thompson, 2015; Vines et al., 2015). Popular narratives specifically problematise the frail elderly, often with reference to crises within the NHS and social care (Donnelly, 2013; Pickles, 2015; Thompson, 2015; Siddique, 2016). The current political climate of economic austerity has resulted in cuts to public services and a focus on rationalising health resources (Iacobucci, 2014; Green et al., 2017). As a result, there is a political drive to identify those at risk of utilising costly services; the recent controversial 
move to offer general practitioners financial incentives to not refer patients to hospital embodies these dynamics (Campbell, 2018).

Geriatric medicine has a long-established tradition of delineating between normal and abnormal ageing in individuals; contemporarily, research and practice has moved towards establishing these divisions at the population level (Katz, 1996; Rowe and Kahn, 1997; Depp and Jeste, 2006). Frailty embodies this trend by attempting to conceptualise variable population ageing (Mitnitski et al., 2001). Frailty's popularity has increased exponentially in recent years, a trajectory reflected by academic literature; in 1998 fewer than ten peer-reviewed articles with the terms 'frailty and elderly' were identified, contrasted with 40 in 1998 and 388 in 2012 (Pickard, 2014). However, a rigorous, universally accepted definition of what frailty actually is remains elusive - a problem frequently acknowledged by biomedical academics (Fried et al., 2001; Ensrud, 2008; Gilleard and Higgs, 2011b). A consensus definition was developed by conference delegates from major international, European and North American societies in 2013, however, it remains vague:

A medical syndrome with multiple causes and contributors that is characterized by diminished strength, endurance, and reduced physiologic function that increases an individual's vulnerability for developing increased dependency and/or death.

(Morley et al., 2013: 392)

Some scholars suggest that rather than pursuing a unifying definition of frailty, researchers should be clear what they mean when they employ the term (Rockwood, 2005; Martin and Brighton, 2008). This infers that frailty is a travelling concept, which can be interpreted, and therefore utilised, variably. This ambiguity represents a fundamental weakness; Bortz (2010: 255) understands frailty as 'an emergent construct' that 'like the weather ... resists facile measurement and definition'. Gilleard and Higgs (2011b: 476) problematise frailty as 'a state of becoming rather than an identity that has been achieved'.

The numerous and ever-expanding approaches to the measurement of frailty described by biomedical researchers are broadly dividable into two dominant conceptual approaches, both of which emerged in the early 2000s: the frailty phenotype (FP) and the deficit accumulation model. The FP understands frailty as a distinct syndrome observable in some older individuals, based on a set of five characteristics: selfreported unintentional weight loss, self-reported exhaustion, weakness (measured by a grip-strength dynamometer), slow walking speed and self-reported low physical activity (Fried et al., 2001). The deficit accumulation model suggests frailty represents the accumulation of physical, psychological and social impairments, which places individuals at risk of adverse outcomes (Mitnitski et al., 2001). This theory is operationalised though the Frailty Index (FI), where deficits are counted and a score allocated based on the proportion of deficits present out of the number of deficits counted. Deficits can include symptoms, signs, functional impairments and laboratory abnormalities; simply accumulating deficits appears to be a robust characteristic that is not sensitive to the choice of particular items (Rockwood et al., 2007).

Both the FP and the FI were developed before the consensus definition. As a result, both conceptual approaches to frailty are validated through prediction of often-costly adverse outcomes such as falls, institutionalisation and mortality. 
Both the FP and the FI have been shown to be independently predictive of death and dependency (Fried et al., 2001; Mitnitski et al., 2001; Boyd et al., 2005; Fugate Woods et al., 2005; Bandeen-Roche et al., 2006; Cawthon et al., 2007). However, when compared in a large-scale study $(\mathrm{N}=2,305)$, the FP and FI showed only moderate correlation for content validity $(R=0.65)$ (Rockwood et al., 2007). This could be taken to infer that the two approaches measure different facets of frailty, however, as the construct in question is so poorly defined, it may suggest the FP and FI are measuring distinct phenomena, thus it appears the conceptual ambiguities surrounding frailty translate methodologically (Martin and Brighton, 2008; Cesari et al., 2014). Indeed, criterion validity is examined through measurements of mortality and institutionalisation; these adverse outcomes occurred more commonly among frail people, irrespective of the measurement tool used. The content validity measurements used in these studies are edifying. By appraising operationalisations of frailty against death and dependency, frailty is positioned as an adverseoutcome risk-identification tool, rather than a discrete syndrome or well-defined clinical entity.

\section{The analytical framework}

Biopower emerged from Foucault's work in the 1970s, where it was used to describe the tactics used to govern lives within contemporary states (Foucault and Senellart, 2008). Biopolitics describes the particular strategies within the field of biopower that make lives knowable and governable (Rabinow and Rose, 2003). As such, biopower and biopolitics are a set of diverse techniques that create ways of knowing and controlling populations and their constituent biological lives (Foucault, 1998). Liberal states focus on welfare promotion for both population and economy; biopolitics is a facet of contemporary governmental practices, employing categorisation strategies to organise lives for the purposes of distinction and division (Walters, 2004). An idea central to Foucault's conceptualisation of the term was that modern liberal states used biopower paradoxically to foster life, whilst concurrently disallowing life to the point of death. Foucault contrasts this with more traditional sovereignty, which he conceptualised as able to 'take life or let live': 'The old power of death that symbolized sovereign power ... was now carefully supplanted by the administration of bodies and the calculated management of life' (Foucault, 1998: 139-140).

In an attempt to provide conceptual clarification, and in critique of others who have used the concept too broadly, Rabinow and Rose (2003) suggest that biopower should be used as an analytical tool and applied to processes which involve three key elements: knowledge of vital life processes, power relations that take humans as living beings as object, and modes of subjectification through which individuals work on themselves. Grenier (2007), Twigg (2004) and Pickard (2014) employed Foucauldian ideas when describing the dynamics around frailty's materialisation and nosology, whilst McCloskey and Van Den Hoonaard (2007) refer to biopolitics in their critical consideration of the social dynamics between nursing home residents and the emergency room. However, a rigorous Foulcauldian analysis of the contemporary emergence and utilisation of frailty has not been undertaken. In arguing that the concept of frailty can be understood as a form of biopower, and 
analysing it as such, this paper will provide a critical and novel perspective on the frailty's conception and the politics of its nosology. Applying Rabinow and Rose's (2003) structured consideration of biopower allows underlying governmental rationale to be critiqued systematically, and problematises some of the assumptions underpinning the utilisation of frailty.

\section{Frailty as a truth discourse}

Rabinow and Rose suggest that biopolitical practices offer:

One or more truth discourses about the 'vital' character of living human beings, and an array of authorities considered competent to speak that truth. These truth discourses ... may hybridize biological and demographic or even sociological styles of thought ... merged in the new language of susceptibility. (Rabinow and Rose, 2003: 3-4)

By narrating older people as a cost, a threat or a burden, increasing age is commonly constructed in relation to risk. For Higgs and Gilleard (2014: 15), 'frail people are seen - at least by others - as being permanently at risk'. This risk is multi-level, ranging from individual to societal, and well as multi-dimensional, spanning ideas of health, economics and, more recently, politics, where older voters are constructed as a challenge to progressive ideology (Walker, 1990; Kharicha et al., 2007; Davidson, 2012; Curtice, 2015; Prince et al., 2015; Dorling, 2016; Aboderin, 2017; Ayalon, 2017; Seo, 2017). Considering older people's risk of falls illustrates how discourses of risk and susceptibility pervade multiple domains and levels. If, for example, an individual is felt by a health-care professional (HCP) to be at risk of falling, they pose a risk to themselves, through the potentiality for consequent illness, injury and death. In turn, family and care-givers see the older individual as at risk, assumptions which have psychological impacts for the older person and their carers, and may also have implications for resources needed for care (Faes et al., 2010; Bauer and Sousa-Poza, 2015). Moreover, falls are understood to pose a risk to society by way of economic threat, through the utilisation of costly health and social care (Heinrich et al., 2010; Tian et al., 2014).

In short, older people are considered simultaneously $a$ risk and at risk; emergent biomedical conceptualisations of frailty capitalise on this dominant ideology. By scoring vital characteristics of older people and generating numerical values that are suggested to relate, albeit at the population level, to risk of decline or death, frailty proffers to quantify risk of decline scientifically. This centralises ideas of risk and augments the discourses around older people's vulnerabilities representing both a burden and a threat. The ability of frailty measurement tools to predict often-costly adverse outcomes results in a subordination of the quest for conceptual clarification. Thus, the ambiguity around what frailty as a biomedical condition actually is becomes obfuscated, and the idea of frailty and its measurement emerges from the aforementioned pieces of quantitative research as a knowable truth discourse.

Despite the British Geriatrics Society stipulating that the routine identification of frailty should not be attempted, the quantification of populations' risk of using finite health-care resources was considered to be to a valuable opportunity 
(British Geriatrics Society, 2014b; Turner and Clegg, 2014). In 2014, an electronic Frailty Index (eFI), based on electronic read codes in patients' GP medical records, was developed. It adopts the FI as its theoretical approach and automatically populates frailty scores from electronic health data in order to categorise individuals routinely as frail, pre-frail or robust (Clegg et al., 2016). Like other measurement tools, the validity of the eFI rests on its prediction of hospitalisation, nursing home admission and all-cause mortality. It is suggested that general practitioners use it in combination with clinical judgement to facilitate decision-making, such as whether to refer for invasive treatment, which may be life-saving but high-risk, and to prompt the initiation of advance care planning for those at risk of death and decline (Afilalo et al., 2012; Clegg et al., 2013; Revenig et al., 2013; Kim et al., 2014; Turner and Clegg, 2014).

This interested policy makers. After imbedding the eFI into electronic GP records in the UK, the routine identification of frailty in all patients over the age of 65 has been incorporated into the most recent NHS England GP contract (NHS England, 2017). The rationale for this is said to centre around improving the quality of care of older people, however, the problems associated with incentivising the application of diagnostic labels on to the older person are multiple. Clinical judgements can become subordinate to arbitrary reductionist biomedical categories, which homogenise diverse groups of individuals with varied health and social needs (Checkland et al., 2008; Pickard, 2013). As Pickard (2013: 978) highlights, a strategy to diagnose routinely older individuals with chronic kidney disease represents 'an extension of surveillance medicine' which transforms a person into a patient. More broadly, the result of incentivising the routine identification of frailty is the institutionalisation of the concept, which promotes its advancement towards becoming a truth discourse (Checkland et al., 2008; Pickard, 2013).

In order to comply with the contract, after the eFI categorises an individual as frail, clinicians must perform a clinical assessment to confirm or refute the diagnostic label. Next they should 'take action' (NHS England, 2017). Such action includes consenting the frail patient for the activation of an Enriched Summary Care Record (ESCR), which allows extensive personal medical information to be shared to a centralised NHS database. Although ESCR are promoted as a way of facilitating continuity of care, the centralisation of personal medical details can be problematic, with the sharing of sensitive information, inaccurate record keeping and data security cited as concerns (Powell et al., 2006; Perera et al., 2011; Spring, 2018; Syal, 2018). Here medical information is accessible, not just to staff at the GP surgery, but to anyone with authorised access, including private companies providing NHS services, researchers and health policy makers (NHS Digital, 2018). As such, the eFI not only offers an enumerated way of quantifying older people's complex needs, it initiates a process that augments experts' knowledge of older individuals' lives.

Pickard (2014) convincingly argues that the contemporary popularity of frailty is inherently linked to the professional ambitions of geriatric medicine. The specialty status of the discipline has historically been questioned, with both scepticism over its significance from outside, and crises of identity from within geriatrics (Reuben et al., 1994; Lanoie Blanchette and Flynn, 2001; Elon, 2006; Denaro and Mudge, 2008; Tinetti, 2016). Frailty legitimises the specialty by centralising geriatricians' 
role in the management of a prevalent complex problem; consequently, the reconfiguration of the profession of geriatric medicine around frailty has been welcomed (Pickard, 2014). In his Marjory Warren lecture at the Annual British Geriatrics Society meeting 2007, Powel stated: 'Marjory Warren may have started with a view to serving all elderly people, but we now focus our attention on the frail, older adult' (Powel, 2007: 607, cited in Pickard, 2014: 557).

Considered against the backdrop of popular narratives which position older people as a threat and a burden to the current shape of health care, frailty capitalises on ideas of 'risk, merged in the new language of susceptibility' and renders individuals' lives knowable (Rabinow and Rose, 2003: 3). The routine identification of frailty represents the utilisation of nosology as a powerful tool, used to facilitate the collection of individuals' detailed biopsychosocial data, which is then accessible for use by multiple governmental bodies. Moreover, in a poignant biopolitical cycle of reaffirmation, expert and governmental endorsement of the predictive power of frailty measurements obfuscate conceptual ambiguities, and position expert geriatric medicine as the professional body competent to speak that particular truth (Rabinow and Rose, 2003).

As a result, frailty emerges as a truth discourse; it is an increasingly pervasive diagnostic label, which is knowable and detectable within clinical practice, and has speciality endorsement. However, in Foucauldian terms, frailty is not a deficit; rather it is an addition, an unwanted 'supplement contributed by disciplinary knowledge and power' (Allen, 2015: 94). Foucault holds that knowledge shapes, regulates and legitimises norms, leaving the social world in a knowable and therefore governable format (Simons, 1995). The creation of designated social groups assists governmental systems by processes and practices that meet and maintain areas of need; this both practically and theoretically maintains the entire regulatory enterprise (Tremain, 2015).

\section{Frailty as a mode of objectification}

Rabinow and Rose's second specification for processes of biopower is that of objectification, whereby there are:

Strategies for intervention upon collective existence in the name of life and health ... addressed to populations that may ... be specified in terms of emergent biosocial collectivities, sometimes specified in terms of categories of race, ethnicity, gender or religion, as in the emerging forms of genetic or biological citizenship. (Rabinow and Rose, 2003: 4)

Foucault considered subjects to be objectivised through dividing practices: 'Examples are the mad and the sane, the sick and the healthy, the criminals and the "good boys"' (Bratich et al., 2003: 154). The process of diagnosis enables clinicians to categorise individuals based on a set of pre-existing characteristics decided by the medical profession; as such, it is a way of creating social order and is associated with the exertion of a significant material force (Blaxter, 1978; Bowker and Star, 2000; Jutel, 2009). By giving order to illness and disease, diagnosis is 
fundamental to the system of modern medicine, allowing physicians to plan therapeutic interventions, estimate prognosis and attribute aetiology.

Diagnostic categories also function as administrative and economic tools by allowing organisations to strategise resources for population health provision. On a more portentous vein, nosology is responsible for creating partitions for corporeal processes and in doing so 'valorises some whilst disregarding others'; the occupation of particular diagnostic categories can make individuals eligible for particular interventions and services, and can exclude them from others (Jutel, 2009: 278). The routine identification of frailty can inform the appropriate selection of elderly people for invasive procedures or drug treatments' (Clegg et al., 2013: 752). Conversely, being deemed too frail can be used as a justification for 'investigative and therapeutic nihilism' (Campbell and Buchner, 1997: 315; Sánchez-Garrido et al., 2016).

All biomedical diagnoses involve processes of delineation and 'power relations that take humans as living beings as their object' (Rabinow and Rose, 2003: 34). However, the practice of routinely categorising older people as either frail or robust is particularly problematic. Unlike other medical conditions with established pathological processes and therapeutic interventions, such as diabetes, frailty is a theoretical state of potential morbidity and mortality (Degnen, 2007). Whilst the biomedical objectives of developing such a risk stratification tool may be noble, even pertinent, the result is that frailty is conceptualised as a metaphorical 'event horizon, beyond which lies the social death of the subject' (Sweeting and Gilhooly, 2008; Higgs and Gilleard, 2014: 10). In other words, unlike agedness, illness and disability, frailty is neither a condition, an identity nor a social position; instead it is the potential of a threatened future (Gilleard and Higgs, 2011a, 2011b). This builds on earlier discussions about how frailty can be understood as a proxy for, and concretisation of, risk; by considering the routine nosology of frailty as a form of objectification, the degree to which the frail are constructed as 'others' destined for failure is highlighted.

Whilst many other diagnostic categories are associated with established management plans, the routine screening for frailty has been met with resistance from HCPs, who have cited concerns about lack of treatment and insufficiently integrated specialist health and social care services for those diagnosed as frail (Shaw et al., 2018). Even seemingly pragmatic basic interventions, such as medication reviews and falls assessments, have not been shown to alter the trajectory of frailty (Turner and Clegg, 2014). The aforementioned conceptual ambiguity of frailty also causes confusion and rejection of the concept, with HCPs questioning the term's usefulness, instead preferring more pragmatic approaches that highlight specific care requirements (Manthorpe and Iliffe, 2015; Gwyther et al., 2018). Frailty is seen by some HCPs as being related to the end of life, and is used in medical notes to justify the refusal of surgery, cardio-pulmonary resuscitation or admission to intensive care (Revenig et al., 2013; BritainThinks et al., 2015; Romero-Ortuno et al., 2016; Haden, 2018).

The lay understanding of frailty carries significant stigma and links with the negative social imaginary of a feared old age' (Gilleard and Higgs, 2011b: 478). Linguistic etymology of the term may be responsible for this in part; the universal lay perception of frailty is one of a negative state of existence, resulting in a social 
stigma that extends beyond its biomedical diagnostic intentions. The Oxford English Dictionary definition of frailty includes:

wanting in power ... unable to resist temptation; habitually falling into transgression ... perishableness ... a frail feature or spot, a flaw ... A fault arising from infirmity; a 'weakness'. (Simpson and Weiner, 1989)

Grenier (2007) argues this connects frailty with powerlessness, impairment and an implication of blame, which inherently causes social devaluation. Older people have reported recognising first-hand experiences of living with frailty and believe they can recognise frailty in others; despite this they avoid the term as a self-identity, due to the perception of frailty as a negative and irreversible label that is associated with end of life (Nicholson et al., 2012; BritainThinks et al., 2015). Moreover, frailty is seen to represent a loss of control, autonomy and independence (Warmoth et al., 2016).

It has been suggested that a diagnosis of frailty attempts to make impairments visible, without acknowledging the lived experiences of physical and personal vulnerability (Grenier, 2007; Grenier and Hanley, 2007). As previously discussed, frailty offers experts ways of making biological lives knowable, but the consequences of this on the objectified individual can be denigrative, even leading to psychological distress (Fillit and Butler, 2009; Puts et al., 2009). Illness-beliefs are associated with a number of adverse outcomes in those with chronic conditions, including self-management and quality of life (Petrie et al., 2007; Richardson et al., 2011). It has been suggested that being diagnosed as frail leads to disengagement with social and physical activities which, in turn, leads to further marginalisation (Warmoth et al., 2016). This disempowering objectification carries the imaginary threat of failure and death, and represents 'profound abjection and the collapse of agency and personal identity'; a superfluous and unwelcome addition to everyday ageism (Fillit and Butler, 2009; Higgs and Gilleard, 2014: 10).

In summary, despite the well-endorsed declaration that 'frailty is the most problematic expression of population ageing', being routinely labelled frail offers little tangible benefit to the individual (Clegg et al., 2013: 752). The linguistic connotation of the terminology has resulted in rejection from older people whilst its contested biomedical utility and unclear management pathways have created resistance amongst some HCP tasked with carrying out processes of categorisation. Frailty is perceived, and consequently lived, as a 'stigmatised cycle of decline', and is a form of objectification most often imposed upon individuals who are largely unable to resist it (Kaufman, 1994; Grenier, 2006; Warmoth et al., 2016: 1490).

\section{Frailty as a mode of subjectification}

The third tenet of Rabinow and Rose's conceptualisation of biopower is that of subjectification. In contrast to objectification, where individuals are worked on by others, subjectification encourages individuals 'to work on themselves, under certain forms of authority, in relation truth discourses ... in the name of individual or collective life or health' (Rabinow and Rose, 2003: 4). Subjectification attempts can be seen throughout biomedical academic literature and policy documents on 
frailty; researchers using the language, and focusing on the strategy, of selfmanagement, defined as the 'ability to obtain those resources necessary for the production of well-being' (Frieswijk et al., 2006: 219; Fairhall et al., 2011; Cramm et al., 2014; Maddocks et al., 2016). The British Geriatrics Society guidance Fit for Frailty suggests:

In terms of modifiable influences, the most studied is physical activity, particularly resistance exercise, which is beneficial both in terms of preventing and treating the physical performance component of frailty. The evidence for diet is less extensive but a suboptimal protein/total calorie intake and vitamin D insufficiency have both been implicated. There is emerging evidence that frailty increases in the presence of obesity particularly in the context of other unhealthy behaviours such as inactivity, a poor diet and smoking. (British Geriatrics Society, 2014a)

Experts' suggested encouragements to older people to self-manage in order to reverse or alter frailty's trajectory are problematic. Thrice-weekly, long-term exercise programmes do not readily translate into existing clinical service structures and may not be acceptable to individuals. Moreover, suggestions are based on methodologically inadequate studies, making questionable claims that frailty is reversible (Liu and Latham, 2009; Theou et al., 2011). This adds to clinicians' scepticism about the usefulness of the routine identification of frailty; unlike many other medical conditions, the causes, prognosis and benefits of therapeutic interventions for frailty for the individual patient are unclear (Rockwood, 2016; Gwyther et al., 2018; Shaw et al., 2018).

Importantly though, the association of frailty with socio-economic deprivation raises ethical concerns about these subjectification attempts. The association between increasing inequalities in both wealth and health in the UK since the introduction of social policies in the 1970s and 1980s have been observed by a number of scholars, who hypothesise that the former is key in determining the latter (Shaw et al., 1999, 2005; Wilkinson and Pickett, 2009; Bennett et al., 2015). Data from the Office for National Statistics supports this inference; men living in the most affluent areas can expect to live disability-free for 15 years longer than their poorest counterparts. The gap in health inequalities continues to increase; years spent with a disability increased for those living in the most deprived areas between 2002-2005 and 2006-2009, though they remained the same for the wealthiest (Office for National Statistics, 2013).

The association between wealth and health is also observable in frailty; poorer groups become frailer at a younger age and socio-economic factors appear to impact the trajectory of frailty, with faster rates of deficit accumulation in poorer groups (Yang and Lee, 2010; Marshall et al., 2015). Other cohort studies have highlighted similar associations; socio-economic deprivation has been linked to poor balance and chair rise times in the UK, and premature gerontological syndromes and increased mortality amongst the poorest has been observed in the United States of America (Kuh et al., 2005; Crimmins et al., 2009; Brown et al., 2012). Recent research demonstrated that frail individuals in lower socio-economic strata have poorer subjective wellbeing than their equally frail but more wealthy counterparts, raising questions about how poverty augments the negative psychological 
impacts of frailty (Hubbard et al., 2014; Warmoth et al., 2018). Moreover, aforementioned self-management strategies are less readily utilised in poorer socioeconomic groups; this is unsurprising, given self-management's intractable relationship to the availability of resources (Cramm et al., 2014).

On-going cuts to 'public spending on a range of social determinants of health under the rhetoric of austerity' means health inequalities are likely to continue to rise, with disadvantaged social groups impacted most (Bennett et al., 2015: 169; Lupton et al., 2015). These structural health inequalities are modifiable at a governmental level; however, despite socio-economic factors being shown to be associated with frailty, biomedical literature rarely reflects this, even correcting for it with statistical analysis, implying an assumption of non-modifiability (Wilkinson and Pickett, 2009). Instead, health policy and biomedical discourses of frailty-prevention strategies largely centre on associations between frailty and individual health behaviours. The association of frailty with socio-economic deprivation raises ethical concerns about these subjectification attempts, especially in the context of populations already marginalised by exclusionary austerity policies.

\section{Conclusion}

The recent dominance of frailty in academic literature and health-care policies demonstrates its popularity amongst many geriatricians and policy makers, however, there are concerns about the concept from other HCPs, scholars and older people themselves. Given the well-described marginalising and disempowering effects of a diagnosis of frailty, it is important to consider critically the contemporary drive to delineate the frail from the robust routinely. This paper has used Rabinow and Rose's model of biopower as a tool to analyse the contemporary conceptualisation and application of frailty as a biopolitical practice; in doing so a number of critical observations have been made about the socio-political dynamics associated with the exponential rise in frailty nosology.

Firstly, despite biomedical experts' acknowledgement of frailty's conceptual ambiguities, the ability of frailty measurements to predict the risk of costly adverse outcomes has made the concept popular. As such, frailty is presented as a truth discourse and the routine identification of frailty is now incentivised, written into the NHS GP contract in 2017. Frailty scores, which embody ideas of risk by digitally enumerating older people's often-complex needs, offer health policy makers a convenient way of knowing a population's constituent biological lives and add legitimacy to the profession of geriatric medicine by positioning geriatricians as frailty experts. Moreover, the routine mass categorisation of particular older people as frail deproblematises the process of the construction of frailty as a social group (Burghardt, 2013).

Secondly, the routine nosology of frailty can be understood as a dividing practice, which results in the objectification of older people. Stigma associated with the lay interpretation of the term means that individuals tend to resist the label, whilst some HCPs have concerns about its value. Scholars have described how frailty represents a feared social imaginary of death and decline, and how this can negatively impact those categorised as frail. Consequently, the diagnosis of frailty can be 
said to benefit those making the diagnosis over those being diagnosed, with the latter becoming objectified and disempowered.

Lastly, like disability and mortality, frailty has been shown to be associated with ever-increasing inequalities in wealth in the UK; these inequalities are the result of governmental ideology, including contemporary austerity policies. Despite these structural inequalities, experts' suggested management of frailty shifts the focus of responsibility away from the state and on to the older person, attempting to encourage individuals to work on themselves through self-management and lifestyle modification. This fails to account for the association between resource availability, lifestyle opportunities and socio-economic factors, thus neglecting the impact of long-term poverty on health. This results in practically and ethically questionable subjectification attempts, aimed at frail older individuals.

Despite these issues, a dominant drive to identify the frailest in a community persists, often presented through discourses which propose benefits for health systems at large (Morley et al., 2013; Turner and Clegg, 2014). In these narratives, the meaning of frailty is subverted; instead of a frail population being inherently vulnerable and in need of protection, it is considered a threat to health-care systems due to the mismatch between frail individuals' multifaceted health issues and the more binary approach to medical treatment offered by health service providers (Rockwood, 2016: 328). Whilst a frail individual is liable to fail, and so requires protection, the process of being offered such protection makes them both an economic risk and a burden to the current configuration of health care.

Whilst acknowledging that in practice many stakeholders position themselves, and indeed move, between the two polemic ideological positions on frailty described in this theoretical analysis, the frame of biopower has facilitated a critical examination of the emergence of frailty. The current political climate of austerity and cuts to public services bring the urgency of this critique to the fore. Contemporarily, the strategic focus of health care centres around rationalising increasingly scarce resources, rather than restructuring services that struggle to address the complex health needs of an ageing population; and rather than describing a pathological condition for the purpose of therapeutic intervention and improving individuals' wellbeing, frailty proffers to identify people most at risk of utilising costly emergency health services. This analysis highlights that although frailty is presented as a biological, scientific truth in quantitative academic literature, its rapid emergence, expert endorsement and routine diagnosis should be carefully considered against the contemporary socio-political environment in the UK. Doing so demonstrates that this biologically ambiguous and etymologically problematic concept has come to occupy a powerful biopolitical position and thus raises concerns about the routine nosology of frailty.

Acknowledgements. I would like to thank Prof. Neil Pendleton, Dr David Bourne, Prof. James Nazroo, Prof. Bertrand Taithe and Dr Rubina Jasani for their thoughtful feedback, which assisted the development of this paper.

Conflict of interest. The author certifies that they have no affiliations with, or involvement in, any organisation or entity with any financial interest (such as honoraria; educational grants; participation in speakers' bureaus; membership, employment, consultancies, stock ownership or other equity interest; and expert 
testimony or patent-licensing arrangements), or non-financial interest (such as personal or professional relationships, affiliations, knowledge or beliefs) in the subject matter or materials discussed in this paper.

Financial support. This paper was developed as part of a doctoral research project which was supported by the Economic and Social Research Council (grant number 9801149).

Ethical standards. Ethical approval was not required.

\section{References}

Aboderin I (2017) Intergenerational Support and Old Age in Africa. Abingdon, UK: Routledge.

Afilalo J, Mottillo S, Eisenberg MJ, Alexander KP, Noiseux N, Perrault LP, Morin J-F, Langlois Y, Ohayon SM, Monette J, Boivin J-F, Shahian DM and Bergman H (2012) Addition of frailty and disability to cardiac surgery risk scores identifies elderly patients at high risk of mortality or major morbidity. Circulation: Cardiovascular Quality and Outcomes 5, 222-228.

Allen B (2015) Foucault's nominalism. In Tremain S (ed.), Foucault and the Government of Disability. Ann Arbor, MI: University of Michigan Press, 93-107.

Ayalon L (2017) Are older adults perceived as a threat to society? Exploring perceived age-based threats in 29 nations. Journals of Gerontology: Psychological Sciences and Social Sciences. https://oi.org/10.1093/ geronb/gbx107.

Bandeen-Roche K, Xue Q-L, Ferrucci L, Walston J, Guralnik JM, Chaves P, Zeger SL and Fried LP (2006) Phenotype of frailty: characterization in the women's health and aging studies. Journals of Gerontology: Biological Sciences and Medical Sciences 61A, 262-266.

Bauer JM and Sousa-Poza A (2015) Impacts of informal caregiving on caregiver employment, health, and family. Journal of Population Ageing 8, 113-145.

Bennett JE, Li G, Foreman K, Best N, Kontis V, Pearson C, Hambly P and Ezzati M (2015) The future of life expectancy and life expectancy inequalities in England and Wales: Bayesian spatiotemporal forecasting. The Lancet 386, 163-170.

Blaxter M (1978) Diagnosis as category and process: the case of alcoholism. Social Science \& Medicine. Part A: Medical Psychology \& Medical Sociology 12, 9-17.

Bortz W (2010) Understanding frailty. The Journals of Gerontology: Medical Sciences 65, 255-256.

Bowker G and Star S (2000) Sorting Things Out: Classification and its Consequences. Cambridge, MA: MIT Press.

Boyd CM, Xue Q-L, Simpson CF, Guralnik JM and Fried LP (2005) Frailty, hospitalization, and progression of disability in a cohort of disabled older women. American Journal of Medicine 118, 1225-1231.

Bratich JZ, Packer J and McCarthy C (2003) Foucault, Cultural Studies, and Governmentality. Albany, NY: State University of New York Press.

British Geriatrics Society (2014a) Causes and Prevention of Frailty. Fit for Frailty. Available at http://www. bgs.org.uk/frailty-cause-prevent/resources/campaigns/fit-for-frailty/frailty-causes-.

British Geriatrics Society (2014b) Frailty in a Routine Situation. Available at http://www.bgs.org.uk/frailtyroutine-sit/resources/campaigns/fit-for-frailty/frailty-identify-routine-situation.

BritainThinks, Age UK and British Geriatrics Society (2015) Frailty: Language and Perceptions (Report prepared on behalf of Age UK and the British Geriatrics Society). London: BritainThinks.

Brown RT, Kiely DK, Bharel M and Mitchell SL (2012) Geriatric syndromes in older homeless adults. Journal of General Internal Medicine 27, 16-22.

Burghardt M (2013) Common frailty, constructed oppression: tensions and debates on the subject of vulnerability. Disability and Society 28, 556-568.

Campbell AJ and Buchner DM (1997) Unstable disability and the fluctuations of frailty. Age and Ageing 26, 315-318.

Campbell D (2015) NHS cannot cope with ageing population, warns top doctor. The Guardian, January 19. Available at https://www.theguardian.com/society/2015/jan/19/nhs-we-have-not-fit-for-future-warnstop-doctor-bruce-keogh.

Campbell D (2018) GPs offered cash to refer fewer people to hospital. The Guardian, February 28. Available at https://www.theguardian.com/society/2018/feb/28/gps-offered-cash-to-refer-fewer-people-to-hospital. 
Cawthon PM, Marshall LM, Michael Y, Dam T-T, Ensrud KE, Barrett-Connor E and Orwoll ES (2007) Frailty in older men: prevalence, progression, and relationship with mortality. Journal of the American Geriatrics Society 55, 1216-1223.

Cesari M, Gambassi G, Van Kan GA and Vellas B (2014) The frailty phenotype and the frailty index: different instruments for different purposes. Age and Ageing 43, 10-12.

Checkland K, Harrison S, McDonald R, Grant S, Campbell S and Guthrie B (2008) Biomedicine, holism and general medical practice: responses to the 2004 GP contract. Sociology of Health and Illness 30, 788-803.

Clegg A, Bates C, Young J, Ryan R, Nichols L, Teale EA, Mohammed MA, Parry J and Marshall T (2016) Development and validation of an electronic frailty index using routine primary care electronic health record data. Age and Ageing 45, 353-360.

Clegg A, Young J, Iliffe S, Rikkert MO and Rockwood K (2013) Frailty in elderly people. Lancet 381, $752-762$.

Cramm JM, Twisk J and Nieboer AP (2014) Self-management abilities and frailty are important for healthy aging among community-dwelling older people; a cross-sectional study. BMC Geriatrics 14, 28.

Crimmins EM, Kim JK and Seeman TE (2009) Poverty and biological risk: the earlier 'aging' of the poor. Journals of Gerontology: Biological Sciences and Medical Sciences 64A, 286-292.

Curtice J (2015) A defeat to reckon with: on Scotland, economic competence, and the complexities of Labour's losses. Juncture 22, 42-47.

Davidson S (2012) Going Grey. Abingdon, UK: Routledge.

Degnen C (2007) Minding the gap: the construction of old age and oldness amongst peers. Journal of Aging Studies 21, 69-80.

Denaro CP and Mudge A (2008) Should geriatric medicine remain a specialty? No. BMJ (Clinical Research Edition) 337, a515.

Depp CA and Jeste DV (2006) Definitions and predictors of successful aging: a comprehensive review of larger quantitative studies. American Journal of Geriatric Psychiatry 14, 6-20.

Donnelly L (2013) Emergency care in crisis admits NHS regulator. The Telegraph. Available at https://www. telegraph.co.uk/news/health/news/10045298/Emergency-care-in-crisis-admits-NHS-regulator.html.

Dorling D (2016) Brexit: the decision of a divided country. BMJ (Clinical Research Edition) 354, i3697.

Elon RD (2006) Perspectives on the future of geriatric medicine. Journal of the American Medical Directors Association 7, 197-200.

Ensrud KE (2008) Comparison of 2 frailty indexes for prediction of falls, disability, fractures, and death in older women. Archives of Internal Medicine 168, 382-389.

Faes MC, Reelick MF, Joosten-Weyn Banningh LW, Gier M de, Esselink RA and Olde Rikkert MG (2010) Qualitative study on the impact of falling in frail older persons and family caregivers: foundations for an intervention to prevent falls. Aging \& Mental Health 14, 834-842.

Fairhall N, Langron C, Sherrington C, Lord SR, Kurrle SE, Lockwood K, Monaghan N, Aggar C, Gill L and Cameron ID (2011) Treating frailty - a practical guide. BMC Medicine 9, 83.

Fillit H and Butler RN (2009) The frailty identity crisis. Journal of the American Geriatrics Society 57, 348352.

Foucault M (1998) The Will to Knowledge. The History of Sexuality, Vol. 1 (Trans. Robert Hurley). London: Penguin.

Foucault M and Senellart M (2008) The Birth of Biopolitics: Lectures at the Collège de France, 1978-79. Basingstoke, UK: Palgrave Macmillan.

Fried LP, Tangen CM, Walston J, Newman AB, Hirsch C, Gottdiener J, Seeman T, Tracy R, Kop WJ, Burke G and McBurnie MA (2001) Frailty in older adults: evidence for a phenotype. Journals of Gerontology: Biological Sciences and Medical Sciences 56A, M146-M157.

Frieswijk N, Steverink N, Buunk BP and Slaets JPJ (2006) The effectiveness of a bibliotherapy in increasing the self-management ability of slightly to moderately frail older people. Patient Education and Counseling 61, 219-227.

Fugate Woods N, LaCroix AZ, Gray SL, Aragaki A, Cochrane BB, Brunner RL, Masaki K, Murray A and Newman AB (2005) Frailty: emergence and consequences in women aged 65 and older in the women's health initiative observational study. Journal of the American Geriatrics Society 53, 1321-1330.

Gilleard C and Higgs P (2011a) Ageing abjection and embodiment in the fourth age. Journal of Aging Studies 25, 135-142. 
Gilleard C and Higgs P (2011b) Frailty, disability and old age: a re-appraisal. Health: An Interdisciplinary Journal for the Social Study of Health, Illness and Medicine 15, 475-490.

Green MA, Dorling D, Minton J and Pickett KE (2017) Could the rise in mortality rates since 2015 be explained by changes in the number of delayed discharges of NHS patients? Journal of Epidemiology and Community Health 71, 1068-1071.

Grenier A (2006) The distinction between being and feeling frail: exploring emotional experiences in health and social care. Journal of Social Work Practice 20, 299-313.

Grenier AM (2007) Constructions of frailty in the English language, care practice and the lived experience. Ageing \& Society 27, 425-445.

Grenier A and Hanley J (2007) Older women and 'frailty'. Current Sociology 55, 211-228.

Gwyther H, Shaw R, Jaime Dauden E-A, D'Avanzo B, Kurpas D, Bujnowska-Fedak M, Kujawa T, Marcucci M, Cano A and Holland C (2018) Understanding frailty: a qualitative study of European healthcare policy-makers' approaches to frailty screening and management. BMJ Open 8, e018653.

Haden A (2018) Frailty, ceilings of treatments and end of life decision making. Available at https://www. rcplondon.ac.uk/file/5167/download?token=V-xdtGBR.

Heinrich S, Rapp K, Rissmann U, Becker C and König H-H (2010) Cost of falls in old age: a systematic review. Osteoporosis International 21, 891-902.

Higgs P and Gilleard C (2014) Frailty, abjection and the 'othering' of the fourth age. Health Sociology Review 23, 10-19.

Hubbard RE, Goodwin VA, Llewellyn DJ, Warmoth K and Lang IA (2014) Frailty, financial resources and subjective well-being in later life. Archives of Gerontology and Geriatrics 58, 364-369.

Iacobucci G (2014) GPs' workload climbs as government austerity agenda bites. BMJ (Clinical Research Edition) 349, g4300.

Jutel A (2009) Sociology of diagnosis: a preliminary review. Sociology of Health \& Illness 31, 278-299.

Katz S (1996) Disciplining Old Age: The Formation of Gerontological Knowledge. Charlottesville, VA: University Press of Virginia.

Kaufman SR (1994) The social construction of frailty: an anthropological perspective. Journal of Aging Studies 8, 45-58.

Kharicha K, Iliffe S, Harari D, Swift C, Gillmann G and Stuck AE (2007) Health risk appraisal in older people 1: are older people living alone an 'at-risk'; group? The British Journal of General Practice: The Journal of the Royal College of General Practitioners 57, 271-276.

Kim S, Han H-S, Jung H, Kim K, Hwang DW, Kang S-B and Kim C-H (2014) Multidimensional frailty score for the prediction of postoperative mortality risk. JAMA Surgery 149, 633.

Kuh D, Bassey EJ, Butterworth S, Hardy R, Wadsworth MEJ and Musculoskeletal Study Team (2005) Grip strength, postural control, and functional leg power in a representative cohort of British men and women: associations with physical activity, health status, and socioeconomic conditions. Journals of Gerontology: Biological Sciences and Medical Sciences 60A, 224-231.

Lanoie Blanchette P and Flynn B (2001) Geriatric medicine: an approaching crisis. Geriatricians 1, 80-84.

Laurence J (2002) Why an ageing population is the greatest threat to society. The Independent. Available at http://www.independent.co.uk/news/uk/home-news/why-an-ageing-population-is-the-greatest-threat-tosociety-5361944.html.

Liu C and Latham NK (2009) Progressive resistance strength training for improving physical function in older adults. Cochrane Database of Systematic Reviews.

Lupton R, Burchardt T, Fitzgerald A, Hills J, Mcknight A, Obolenskaya P, Stewart K, Thomson S, Tunstall R and Vizard P (2015) The Coalition's social policy record: policy, spending and outcomes 2010-2015. Social policy in a cold climate research report, SPCCRR04. London, UK: Centre for Analysis of Social Exclusion, London School of Economics and Political Science. Available at: http://sticerd.lse.ac.uk/case/.

Maddocks M, Kon SSC, Canavan JL, Jones SE, Nolan CM, Labey A, Polkey MI and Man WD-C (2016) Physical frailty and pulmonary rehabilitation in COPD: a prospective cohort study. Thorax 71, 988-995.

Manthorpe J and Iliffe S (2015) Frailty - from bedside to buzzword? Journal of Integrated Care 23, $120-128$. 
Marshall A, Nazroo J, Tampubolon G and Vanhoutte B (2015) Cohort differences in the levels and trajectories of frailty among older people in England. Journal of Epidemiology and Community Health 69, 316-321.

Martin FC and Brighton P (2008) Frailty: different tools for different purposes? Age and Ageing 37, 129-131.

McCloskey R and Van Den Hoonaard D (2007) Nursing home residents in emergency departments: a Foucauldian analysis. Journal of Advanced Nursing 59, 186-194.

Mitnitski AB, Mogilner AJ and Rockwood K (2001) Accumulation of deficits as a proxy measure of aging. The Scientific World Journal 1, 323-336.

Morley JE, Vellas B, van Kan GA, Anker SD, Bauer JM, Bernabei R, Cesari M, Chumlea WC, Doehner W, Evans J, Fried LP, Guralnik JM, Katz PR, Malmstrom TK, McCarter RJ, Gutierrez Robledo LM, Rockwood K, von Haehling S, Vandewoude MF and Walston J (2013) Frailty consensus: a call to action. Journal of the American Medical Directors Association 14, 392-397.

NHS Digital (2018) Summary Care Records (SCR). Available at https://digital.nhs.uk/summary-care-records.

NHS England (2017) Supporting Routine Frailty Identification and Frailty Through the GP Contract 2017/ 2018. Available at https://www.england.nhs.uk/publication/supporting-routine-frailty-identification-andfrailty-through-the-gp-contract-20172018/.

Nicholson C, Meyer J, Flatley M, Holman C and Lowton K (2012) Living on the margin: understanding the experience of living and dying with frailty in old age. Social Science \& Medicine 75, 1426-1432.

Office for National Statistics (2013) Inequality in disability-free life expectancy by area deprivation: England, 2003-06 and 2007-10. Subnational Health Expectancies Experimental Statistics Statistical Bulletin 1-22. Available at https://www.ons.gov.uk/peoplepopulationandcommunity/healthandsocialcare/healthandlifeexpectancies/bulletins/inequalityindisabilityfreelifeexpectancybyareadeprivationengland/2013-07-25.

Office for National Statistics (2017) Overview of the UK Population. Available at https://www.ons.gov. $\mathrm{uk} /$ peoplepopulationandcommunity/populationandmigration/populationestimates/articles/overviewoftheukpopulation/july2017.

Perera G, Holbrook A, Thabane L, Foster G and Willison DJ (2011) Views on health information sharing and privacy from primary care practices using electronic medical records. International Journal of Medical Informatics 80, 94-101.

Petrie KJ, Jago LA and Devcich DA (2007) The role of illness perceptions in patients with medical conditions. Current Opinion in Psychiatry 20, 163-167.

Pickard S (2013) A new political anatomy of the older body? An examination of approaches to illness in old age in primary care. Ageing \& Society 33, 964-987.

Pickard S (2014) Frail bodies: geriatric medicine and the constitution of the fourth age. Sociology of Health \& Illness 36, 549-563.

Pickles K (2015) NHS A\&E targets missed as 'frail and elderly' are blamed for record bedblocking levels. Mail Online. Available at http://www.dailymail.co.uk/health/article-3354443/NHS-winter-crisis-deepensE-targets-missed-frail-elderly-blamed-bedblocking-levels-reaching-record-highs.html.

Powel C (2007) Whither geriatrics? Do we need another Marjory Warren? Age and Ageing 36, 607-610.

Powell J, Fitton R and Fitton C (2006) Sharing electronic health records: the patient view. Journal of Innovation in Health Informatics 14, 55-57.

Press Association (2005) Ageing population 'will strain NHS resources'. The Guardian, December 9. Available at https://www.theguardian.com/society/2005/dec/09/health.politics.

Prince MJ, Wu F, Guo Y, Gutierrez Robledo LM, O'Donnell M, Sullivan R and Yusuf S (2015) The burden of disease in older people and implications for health policy and practice. The Lancet 385, 549-562.

Puts MTE, Shekary N, Widdershoven G, Heldens J and Deeg DJH (2009) The meaning of frailty according to Dutch older frail and non-frail persons. Journal of Aging Studies 23, 258-266.

Rabinow P and Rose N (2003) Thoughts on the concept of biopower today. Paper presented at the Vital Politics: Health, Medicine and Bioeconomics into the Twenty-first Century conference, 5-7 September, London.

Reuben DB, Zwanziger J, Bradley TB and Beck JC (1994) Is geriatrics a primary care or subspecialty discipline? Journal of the American Geriatrics Society 42, 363-367. 
Revenig LM, Canter DJ, Taylor MD, Tai C, Sweeney JF, Sarmiento JM, Kooby DA, Maithel SK, Master VA and Ogan K (2013) Too frail for surgery? Initial results of a large multidisciplinary prospective study examining preoperative variables predictive of poor surgical outcomes. Journal of the American College of Surgeons 217, 665-670.

Richardson S, Karunananthan S and Bergman H (2011) I may be frail but I ain't no failure. Canadian Geriatrics Journal 14, 24-28.

Rockwood K (2005) Frailty and its definition: a worthy challenge. Journal of the American Geriatrics Society 53, 1069-1070.

Rockwood K (2016) Screening for grades of frailty using electronic health records: where do we go from here? Age and Ageing 45, 328-329.

Rockwood K, Andrew M and Mitnitski A (2007) A comparison of two approaches to measuring frailty in elderly people. Journals of Gerontology: Biological Sciences and Medical Sciences 62A, 738-743.

Romero-Ortuno R, Wallis S, Biram R and Keevil V (2016) Clinical frailty adds to acute illness severity in predicting mortality in hospitalized older adults: an observational study. European Journal of Internal Medicine 35, 24-34.

Rowe JW and Kahn RL (1997) Successful aging. The Gerontologist 37, 433-440.

Sánchez-Garrido N, Cesari M, Sgaravatti A, Zengarini E, Moreira V, Borda M-G, Zúñiga-Gil C and Pérez-Zepeda MU (2016) The chimeric nihilism of geriatrics. Journal of the American Geriatrics Society 64, e213-e214.

Seo Y (2017) Democracy in the ageing society: quest for political equilibrium between generations. Futures 85, 42-57.

Shaw M, Davey Smith G and Dorling D (2005) Health inequalities and New Labour: how the promises compare with real progress. BMJ (Clinical Research Edition) 330, 1016-1021.

Shaw M, Dorling D, Gordon D and Smith GD (1999) The Widening Gap: Health Inequalities and Policy in Britain. Bristol, UK: Policy Press.

Shaw R, Gwyther H, Holland C, Bujnowska-Fedak M, Kurpas D, Cano A, Marcucci M, Riva S and D'avanzo B (2018) Understanding frailty: meanings and beliefs about screening and prevention across key stakeholder groups in Europe. Ageing \& Society 38, 1223-1252.

Siddique H (2016) NHS 'bedblocking' rises for sixth month in a row. The Guardian, November 10. Available at https://www.theguardian.com/society/2016/nov/10/nhs-bed-blocking-rises-sixth-month-patientshospital.

Silcock D and Sinclair D (2012) The Cost of Our Ageing Society. London: ILC-UK.

Simons J (1995) Foucault and the Political. London: Routledge.

Simpson JA and Weiner ESC (1989) The Oxford English Dictionary, 2nd Edn. Oxford: Oxford University Press.

Spring M (2018) Enriched Summary Care Records. Royal College of General Practitioners. Available at http://www.rcgp.org.uk/clinical-and-research/bright-ideas/enriched-summary-care-records-dr-markspring.aspx.

Sweeting H and Gilhooly M (2008) Dementia and the phenomenon of social death. Sociology of Health \& Illness 19, 93-117.

Syal R (2018) Every NHS trust tested for cybersecurity has failed, officials admit. The Guardian, February 5. Available at https://www.theguardian.com/technology/2018/feb/05/every-nhs-trust-tested-for-cybersecurity-has-failed-officials-admit.

Theou O, Stathokostas L, Roland KP, Jakobi JM, Patterson C, Vandervoort AA and Jones GR (2011) The effectiveness of exercise interventions for the management of frailty: a systematic review. Journal of Aging Research 2011, 569194.

Thompson C (2015a) Meeting the Challenges of an Ageing Population. NHS England Online Blog. Available at https://www.england.nhs.uk/blog/catherine-thompson/.

Tian Y, Thompson J and Buck D (2014) The cost of falls. Journal of Integrated Care 22, 165-173.

Tinetti M (2016) Mainstream or extinction: can defining who we are save geriatrics? Journal of the American Geriatrics Society 64, 1400-1404.

Tremain S (ed.) (2015) Foucault and the Government of Disability. Ann Arbor, MI: University of Michigan Press.

Turner G and Clegg A (2014) Best practice guidelines for the management of frailty: a British Geriatrics Society, Age UK and Royal College of General Practitioners report. Age and Ageing 43, 744-747. 
Twigg J (2004) The body, gender, and age: Feminist insights in social gerontology. Journal of Aging Studies 18, 59-73.

Vines J, Pritchard G, Wright P, Olivier P and Brittain K (2015) An age-old problem: examining the discourses of ageing in $\mathrm{HCI}$ and strategies for future. ACM Transactions on Computer-Human Interaction 22, 1-2.

Walker A (1990) The economic 'burden' of ageing and the prospect of intergenerational conflict. Ageing \& Society 10, 377-396.

Walters W (2004) Secure borders, safe haven, domopolitics. Citizenship Studies 8, 237-260.

Warmoth K, Lang I, Phoenix C, Abraham C, Andrew MK, Hubbard R and Tarrant M (2016) 'Thinking you're old and frail': a qualitative study of frailty in older adults. Ageing \& Society 36, 1483-1500.

Warmoth K, Tarrant M, Abraham C and Lang IA (2018) Relationship between perceptions of ageing and frailty in English older adults. Psychology, Health \& Medicine 23, 465-474.

Wilkinson R and Pickett K (2009) The Spirit Level: Why More Equal Societies Almost Always Do Better. London: Penguin.

Yang Y and Lee LC (2010) Dynamics and heterogeneity in the process of human frailty and aging: evidence from the U.S. older adult population. Journals of Gerontology: Psychological Sciences and Social Sciences 65B, 246-255.

Cite this article: Tomkow L (2020). The emergence and utilisation of frailty in the United Kingdom: a contemporary biopolitical practice. Ageing \& Society 40, 695-712. https://doi.org/10.1017/S0144686X18001319 